\title{
(6) OPEN ACCESS \\ Personal pack display and active smoking at outdoor café strips: assessing the impact of plain packaging 1 year postimplementation
}

\author{
Meghan Zacher, ${ }^{1}$ Megan Bayly, ${ }_{1}$ Emily Brennan, ${ }^{1}$ Joanne Dono, ${ }^{2}$ Caroline Miller, ${ }^{2,3}$ \\ Sarah Durkin, ${ }^{1}$ Michelle Scollo, ${ }^{1}$ Melanie Wakefield ${ }^{1}$
}

${ }^{1}$ Cancer Council Victoria, Melbourne, Victoria, Australia ${ }^{2}$ South Australian Health and Medical Research Institute, Adelaide, South Australia, Australia

${ }^{3}$ Discipline of Public Health, University of Adelaide, Adelaide, South Australia, Australia

\section{Correspondence to} Professor Melanie Wakefield, Centre for Behavioural Research in Cancer, Cancer Council Victoria, 615 St Kilda Road, Melbourne, VIC 3004, Australia; melanie.wakefield@ cancervic.org.au

Received 5 June 2014 Accepted 27 August 2014
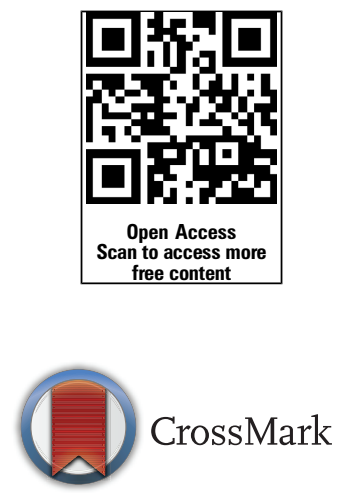

To cite: Zacher M, Bayly M, Brennan $\mathrm{E}$, et al. Tob Control 2015:24:ii94-ii97.

\section{ABSTRACT}

Aims We observed tobacco pack display and smoking at outdoor venues over three summers to assess changes in their prevalence following Australia's introduction of plain tobacco packaging with larger pictorial health warnings.

Methods Between January and April 2012 (preplain packaging (PP)), 2013 (early post-PP) and 2014 (1 year post-PP), we counted patrons, smokers and tobacco packs at cafés, restaurants and bars with outdoor seating. Pack type (branded, plain or unknown) and orientation were noted. Rates of active smoking, pack display and pack orientation were analysed using multilevel Poisson regression.

Results Prevalence of pack display among patrons declined from pre-PP (1 pack per 8.7 patrons) to early post-PP (1 pack per 10.4), and remained low 1 year post-PP (1 pack per 10.3). This appeared to be driven by a sustained decline in active smoking post-PP (pre-PP: $8.4 \%$ of patrons were smoking; early post-PP: $6.4 \%$; 1 year post-PP: $6.8 \%$ ). Notably, active smoking declined more in venues with children present than in those without. While early post-PP, plain packs were less often displayed face-up (74.0\%) and more often concealed (8.9\%) than branded packs pre-PP (face-up: $85.2 \%$; concealed: $4.0 \%$ ), this was not sustained 1 year post-PP (face-up: 85.7\%; concealed: 4.4\%). Also, external case use increased from pre-PP (1.2\%) to early post-PP (3.5\%), but returned to pre-PP levels 1 year post-PP (1.9\%).

Conclusions This study demonstrated a sustained reduction in visibility of tobacco products and smoking in public, particularly in the presence of children, from pre-PP to 1 year post-PP. This effect is likely to reduce smokingrelated social norms, thereby weakening an important influence on smoking uptake and better supporting quit attempts.

\section{INTRODUCTION}

In two recent studies, ${ }^{1}{ }^{2}$ we monitored prevalence and nature of personal tobacco pack display and smoking in outdoor areas of cafés, restaurants and bars in two Australian cities (Melbourne and Adelaide) in order to evaluate whether such behaviours were more common in a branded environment than under plain packaging (PP), which was fully implemented in Australia on 1 December 2012. ${ }^{3}$ We found that prevalence of pack display and active smoking declined from pre-PP (October 2011 to April 2012) to early post-PP (October 2012 to April 2013), particularly in the presence of children. ${ }^{2}$ Packs were also less often oriented face-up early post-PP, and were more likely to be concealed with an object placed on top, or in an external case. The current study extends these findings by assessing whether these changes were sustained 1 year after PP was introduced.

\section{METHODS}

Details regarding sample selection and data collection for the pre-PP and early post-PP phases have been described elsewhere, ${ }^{12}$ and similar methods were used for the 1 year post-PP phase. Briefly, for the pre-PP phase we selected street segments (referred to as 'café strips') from a range of socioeconomic areas in Melbourne and Adelaide that were known to have many popular cafés, restaurants and bars. Fieldworkers sampled every venue in their assigned café strip/s which had outdoor seating visible from the footpath. New venues were added to the sample if they had opened between phases.

Between mid-October and mid-April of 20112012 (pre-PP) and 2012-2013 (early post-PP), fieldworkers conducted nine waves of observations at approximately 2-week intervals, achieving high interrater reliability. ${ }^{2}$ For the 1 year post-PP phase, five waves of data were collected at approximately 2 -week intervals between mid-January and mid-April 2014.

At each venue, fieldworkers counted the number of seated patrons, patrons smoking, holding or lighting a cigarette ('active smokers'), and tobacco packs, noting the pack type in the post-PP phases (branded, plain or unknown). They also recorded whether children were present, how many packs were oriented face-up with the brand name and variant visible, face-down, standing or on their side or concealed by an object like a wallet or phone (by pack type), and how many packs were in an unknown orientation due to distance or an external case (not recorded by pack type).

\section{Statistical analysis}

We used data from the five waves in each of the three phases that were conducted between January and April. Preliminary analyses confirmed that restricting the pre-PP and early post-PP periods to the five waves of data did not substantially change the results from those previously published for these periods. ${ }^{1} 2$ Multilevel Poisson models were employed in Stata $12.1^{4}$ to test whether outcomes of interest 1 year post-PP were different than pre-PP and early post-PP. We report Bonferroni-adjusted $\mathrm{p}$ values to account for multiple comparisons. Random intercepts were included for café strip and venue in all models to adjust SEs for correlations among venues within the 
same café strip and for multiple observations over time within the same venue. All models adjusted for city, area SES using an Index of Relative Disadvantage, ${ }^{5}$ presence of children, month (January, February and March/April), day and time (weekdays before 16:00, weekdays after 16:00, and weekends), temperature $\left(<22^{\circ} \mathrm{C}, 22-27^{\circ} \mathrm{C}, \geq 28^{\circ} \mathrm{C}\right.$ ), and wind speed (in $\mathrm{km} / \mathrm{h}$ ).

To analyse outcomes as rates, offset terms were used. Number of patrons was the offset term for the rates of packs to patrons and smokers to patrons; at least one patron had to be recorded for an observation to be analysed. Similarly, number of smokers was the offset for the rate of packs to smokers, and only observations with one or more smokers present were included. We compared rates of face-up orientation and pack concealment among branded packs pre-PP to rates among plain packs post-PP. As it was impossible to tell in the post-PP phases whether packs in external cases and those packs in unknown orientation (due to distance) were plain or branded, they could not be included in these analyses. Accordingly, the equivalent packs were excluded from the pre-PP data, so that denominators were comparable with the post-PP phases. Only observations for which at least one known-orientation branded (pre-PP) or plain (early or 1 year post-PP) pack was recorded were analysed. The rate of external case use was analysed out of all observed packs; accordingly, at least one pack had to be observed to be analysed. We also tested whether declines in pack display and active smoking among patrons between pre-PP and 1 year post-PP were again greater in venues with children present than in those without. Finally, we conducted sensitivity analyses to assess whether excluding venues which were not observed in all three phases altered our results.

\section{RESULTS}

In total, 585 unique venues were observed over the course of the study, of which 519 venues had patrons present at least once. There were 6997 observations from these venues (pre-PP: $\mathrm{n}=2189$; early post-PP: $\mathrm{n}=2367 ; 1$ year post-PP: $\mathrm{n}=2441$ ), though many $(n=3050)$ were not included in regression analyses as no patrons were present. Patrons were present at a total of 3947 venue observations (pre-PP: $n=1340$; early post-PP: $n=1296$; 1 year post-PP: $n=1311$ ). Fewer venue observations were used in analyses of the rates of packs to active smokers $(\mathrm{n}=1195)$, face-up and concealed packs to known-orientation branded (pre-PP) or plain (post-PP) packs $(n=1381)$, and external cases to all packs $(n=1470)$.

\section{Prevalence of pack display and active smoking}

The rate of pack display among patrons was lower in the early post-PP phase and 1 year post-PP compared with pre-PP, and there was no change between early and 1 year post-PP (table 1 ). While one in every 8.7 patrons displayed a pack pre-PP, this declined to one in every 10.4 patrons early post-PP and one in every 10.3 patrons 1 year post-PP. Prevalence of active smoking also declined, from $8.4 \%$ of patrons pre-PP to $6.4 \%$ early post-PP and remained lower (at 6.8\%) 1 year post-PP. The rate of pack display relative to active smokers (not shown in table 1) did not change between pre-PP and early post-PP (Incident Rate Ratio $(I R R)=1.03, p=1.000)$ or between pre-PP and 1 year post-PP $(I R R=0.95, p=1.000)$. In each phase, there was one pack observed for every 0.7 active smokers (thus, there were more packs displayed than there were patrons actively smoking).

There was a significant interaction for the rate of active smoking among patrons between pre-PP and 1 year post-PP and the presence of children at a venue $(\mathrm{p}=0.015)$, with a greater decline in venues with children present $(\operatorname{IRR}=0.47, \mathrm{p}<0.001)$ than in those without $(\mathrm{IRR}=0.88, \mathrm{p}=.058$ ) (figure 1$)$. A similar pattern was observed by presence of children for pack display

Table 1 Changes in personal pack display, active smoking and pack orientation between preplain packaging (January-April 2012), and early (January-April 2013) and 1 year ( January-April 2014) post-plain packaging

\begin{tabular}{|c|c|c|c|c|c|c|}
\hline \multirow[b]{2}{*}{ Outcome (rate of...) } & \multirow[b]{2}{*}{ Rate } & \multirow[b]{2}{*}{ Percentage of... } & \multicolumn{2}{|l|}{ Versus pre-PP } & \multicolumn{2}{|c|}{ Versus early post-PP } \\
\hline & & & Adjusted IRR & p Value* & Adjusted IRR & p Value* \\
\hline Packs to patrons & & ...patrons who displayed pack & & & & \\
\hline Pre-PP & $1: 8.7$ & 11.5 & Ref & & 1.21 & $<0.001$ \\
\hline Early post-PP & $1: 10.4$ & 9.7 & 0.83 & $<0.001$ & Ref & \\
\hline 1 year post-PP & $1: 10.3$ & 9.7 & 0.84 & 0.001 & 1.02 & 1.000 \\
\hline Active smokers to patrons & & ...patrons who were smoking & & & & \\
\hline Pre-PP & $1: 11.9$ & 8.4 & Ref & & 1.28 & $<0.001$ \\
\hline Early post-PP & $1: 15.7$ & 6.4 & 0.78 & $<0.001$ & Ref & \\
\hline 1 year post-PP & $1: 14.7$ & 6.8 & 0.85 & 0.013 & 1.08 & 0.607 \\
\hline Face-up packs to all packst & & ...packst that were face-up & & & & \\
\hline Pre-PP & 1:1.2 & 85.2 & Ref & & 1.15 & 0.037 \\
\hline Early post-PP & 1:1.4 & 74.0 & 0.87 & 0.037 & Ref & \\
\hline 1 year post-PP & $1: 1.2$ & 85.7 & 0.99 & 1.000 & 1.14 & 0.087 \\
\hline Concealed packs to all packst & & ...packst that were concealed & & & & \\
\hline Pre-PP & $1: 25.3$ & 4.0 & Ref & & 0.40 & $<0.001$ \\
\hline Early post-PP & $1: 11.3$ & 8.9 & 2.48 & $<0.001$ & Ref & \\
\hline 1 year post-PP & $1: 22.5$ & 4.4 & 1.22 & 1.000 & 0.49 & 0.005 \\
\hline External cases to all packs & & ...packs that were in cases & & & & \\
\hline Pre-PP & $1: 83.1$ & 1.2 & Ref & & 0.29 & 0.001 \\
\hline Early post-PP & $1: 28.3$ & 3.5 & 3.44 & 0.001 & Ref & \\
\hline 1 year post-PP & $1: 52.2$ & 1.9 & 1.36 & 1.000 & 0.40 & 0.012 \\
\hline
\end{tabular}




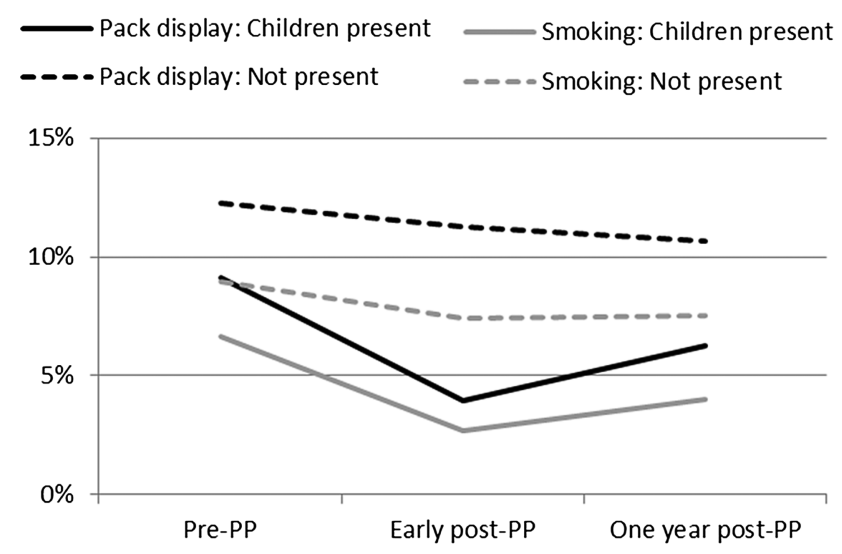

Figure 1 Percentage of patrons who displayed a pack (pack display) and percentage of patrons actively smoking (smoking), by phase and presence of children at venue.

among patrons, but the interaction was not significant $(\mathrm{p}=0.211$; figure 1$)$.

\section{Pack orientation}

The percentage of packs oriented face-up declined from pre-PP (branded packs: $85.2 \%$ ) to early post-PP (plain packs: $74.0 \%$ ), but returned to the baseline level 1 year post-PP (plain packs: 85.7\%; tables 1 and 2). Similarly, while pack concealment increased between the pre-PP (branded packs: $4.0 \%$ ) and early post-PP (plain packs: $8.9 \%$ ) phases, concealment resumed its baseline level by 1 year post-PP (plain packs: 4.4\%). Finally, though prevalence of use of external cigarette cases increased between pre-PP (1.2\%) and early post-PP (3.5\%), at 1 year post-PP $(1.9 \%)$ it was no different to pre-PP.

\section{Sensitivity analyses}

Of the 519 venues observed that had patrons present at least once, 10 were not observed in one or both of the post-PP phases, as they banned smoking in outdoor areas, and an additional 161 venues were not open for business in all three phases. Sensitivity analyses excluding all observations from venues which banned smoking outdoors or which were not open for business in all three phases obtained results similar to those of the main analysis.

\section{DISCUSSION}

The results of this study extend previous findings ${ }^{2}$ by confirming that declines in personal pack display and active smoking at outdoor public venues were maintained 1 year after the introduction of plain tobacco packaging with refreshed and enlarged graphic health warnings (GHWs). While 1 in every 8.7 patrons displayed a tobacco pack pre-PP, this declined to 1 in 10.4 patrons early post-PP and 1 in 10.3 patrons 1 year post-PP. Prevalence of active smoking declined from $8.4 \%$ of patrons pre-PP to $6.4 \%$ early post-PP and $6.8 \% 1$ year post-PP. These findings are consistent with naturalistic studies which have found that, when told to carry mocked-up plain packs with large GHWs, smokers smoked less around others and were more likely to forgo cigarettes than when carrying their regular branded packs. ${ }^{6}{ }^{7}$ It is also notable that, consistent with effects observed between pre-PP and early post-PP, ${ }^{2}$ there were greater declines pre-PP to 1 year post-PP in active smoking at venues where children were present. This suggests an enhancement of social pressure to forego smoking when children are present.

Findings reported here are consistent with those of experimental and descriptive research which has shown that plain packs are less appealing and convey more negative characteristics of smokers than traditional branded packs. ${ }^{8} 9$ Smokers may have chosen to light up less often in public after plain packs were introduced to elude being judged by passers-by or to avoid feelings of shame or embarrassment. Observed declines in pack display and active smoking could also reflect the reduced prevalence of population smoking over time, evident from recently released national survey data showing a reduction in $14+$ years daily smoking from $15.1 \%$ in 2010 to $12.8 \%$ in $2013 .^{10}$

Changes in pack orientation that were observed early post-PP were not sustained 1 year post-PP. These findings may indicate that the use of external cases became more of a nuisance over time and/or that the salience of the larger front-of-pack GHWs and impact of the removal of reassuring brand imagery decreased over time (reducing smokers' motivation to conceal the packs); a wear-out effect that would be expected. ${ }^{11}$ However, a positive consequence of these findings is that less pack concealment 1 year post-PP means that the owner of the pack, other smokers, and non-smokers are more frequently exposed in an incidental manner to the large graphic warning images.

One limitation of the study is that there was a substantial increase in tobacco excise and customs duties on 1 December 2013, which could have independently resulted in smokers

Table 2 Pack orientations, by phase and pack type

\begin{tabular}{|c|c|c|c|c|c|c|c|c|}
\hline & \multicolumn{2}{|c|}{ Pre-plain packaging } & \multicolumn{3}{|c|}{ Early post-plain packaging } & \multicolumn{3}{|c|}{1 year post-plain packaging } \\
\hline & All packs & Branded packs* & All packst & Plain packs & Branded packs & All packst & Plain packs & Branded packs \\
\hline Total N & 1164 & 1112 & 907 & 788 & 33 & 940 & 854 & 43 \\
\hline \multicolumn{9}{|l|}{ Orientation (\%) } \\
\hline Face-up & 81.4 & 85.2 & 67.5 & 74.0 & 84.8 & 82.0 & 85.7 & 86.0 \\
\hline Face-down & 8.0 & 8.4 & 11.7 & 12.9 & 12.1 & 7.2 & 7.7 & 4.7 \\
\hline Standing & 2.4 & 2.5 & 3.7 & 4.2 & 0.0 & 2.1 & 2.1 & 2.3 \\
\hline Concealed & 3.8 & 4.0 & 9.7 & 8.9 & 3.0 & 5.0 & 4.4 & 7.0 \\
\hline External case & 1.2 & - & 3.5 & - & - & 1.9 & - & - \\
\hline Undetermined & 3.3 & - & 3.9 & - & - & 1.7 & - & - \\
\hline
\end{tabular}

${ }^{*}$ At pre-plain packaging, 'Branded packs' excludes packs in external cases and undetermined orientations, which would have been recorded as an unknown packaging type in the post-plain packaging phases. This means that the three phases have equivalent denominators.

†At post-plain packaging, 'All packs' includes plain and branded packs as well as packs of unknown type (early post-PP: $n=86$; 1 year post-PP: $n=43$ ). 0 f these unknown type packs, the majority were coded as having an undetermined orientation or were in an external case. Some were concealed, and a small number ( 2 in early post-plain packaging and 3 in 1 year post-plain packaging) had valid data for pack orientation but missing data for the pack type variable.

$\mathrm{PP}$, plain packaging. 
decreasing their consumption or trying to quit in the early months of 2014. ${ }^{12}{ }^{13}$ Similarly, the decline in pack display might also reflect lower willingness to risk being asked to share a cigarette as the price of tobacco increases, although the lower display rates when children are present tends to support more of a social pressure interpretation. Another limitation is that we only observed behaviours in two metropolitan areas, and so cannot generalise our results nationally. However, a strength of our study is that outcomes are not subject to social desirability bias or misreporting, and reflect behaviours and the visibility of tobacco products and smoking in real-world scenarios.

The visibility of tobacco use in public places is increasingly receiving research attention as an indicator of de-normalisation. ${ }^{14-16}$ Lower rates of exposure (particularly among children) to smoking in public is likely to influence social norms for tobacco use. ${ }^{17}$ Also, the reduction in visible smoking-related cues may aid quit attempts. ${ }^{18} 19$ Our finding of a sustained reduction 1 year after PP implementation in the frequency of pack display and active smoking in public venues may therefore have positive impacts both for those trying to quit and ultimately, for reducing smoking uptake.

\section{What this paper adds}

- Rates of personal tobacco pack display and active smoking among patrons in outdoor areas of cafes, restaurants and bars remained lower 1 year after the implementation of plain packaging in Australia compared to the summer before implementation.

- Though packs were less likely to be face-up and more likely to be concealed or in external cases immediately following implementation, these orientations returned to baseline levels 1 year post-implementation.

Acknowledgements The authors thank staff of Cancer Council Victoria, Cancer Council South Australia, and South Australian Health and Medical Research Institute who undertook data collection.

Contributors MW and MS conceived the study; MZ, MB, EB and SD improved its design; MZ, MB, JD and CM coordinated aspects of data collection; MZ undertook data analysis; MW and MZ drafted the manuscript; all authors revised the manuscript and have read and approved the final version.

Funding This study was funded by Cancer Council Victoria, Cancer Council South Australia, South Australian Health and Medical Research Institute, and Quit Victoria.

Competing interests The authors wish to advise that MW was a member and MS a technical writer for the Tobacco Working Group of the Australian National Preventive Health Task Force and MW was a member of the Expert Advisory Committee on Plain Packaging that advised the Australian Department of Health on research pertaining to the plain packaging legislation. MW, SD and EB hold competitive grant funding from the Australian National Health and Medical Research Council, MW and CM hold such funding from Cancer Council South Australia and MW holds such funding from the US National Institutes of Health, Australian National Preventive Health Agency and BUPA Health Foundation.
Ethics approval This was an unobtrusive observational study counting café patrons and cigarette packs and was conducted in a public setting.

Provenance and peer review Not commissioned; externally peer reviewed.

Open Access This is an Open Access article distributed in accordance with the Creative Commons Attribution Non Commercial (CC BY-NC 4.0) license, which permits others to distribute, remix, adapt, build upon this work non-commercially, and license their derivative works on different terms, provided the original work is properly cited and the use is non-commercial. See: http://creativecommons.org/ licenses/by-nc/4.0/

\section{REFERENCES}

1 Wakefield M, Zacher M, Bayly M, et al. The silent salesman: an observational study of personal tobacco pack display at outdoor café strips in Australia. Tob Control 2014;23:339-44

2 Zacher M, Bayly M, Brennan E, et al. Personal tobacco pack display before and after the introduction of plain packaging with larger pictorial health warnings in Australia: an observational study of outdoor café strips. Addiction 2014; 109:653-62.

3 Tobacco Plain Packaging Act 2011 (Cth), Stat. No. 148 (2011). http://www.austlii. edu.au/au/legis/cth/num_act/tppa2011180/

4 StataCorp. Stata Statistical Software: Release 12. College Station, TX: StataCorp LP, 2011.

5 Australia Bureau of Statistics. Technical paper: socio-economic indexes for areas (SEIFA) 2011 Catalogue no. 2033.0.55.001. Canberra, Australia: Australian Bureau of Statistics, 2013

6 Moodie CS, Mackintosh AM. Young adult women smokers' response to using plain cigarette packaging: a naturalistic approach. BMJ Open 2013;3:e002402.

7 Moodie C, Mackintosh AM, Hastings G, et al. Young adult smokers' perceptions of plain packaging: a pilot naturalistic study. Tob Control 2011;20:367-73.

8 Moodie C, Stead M, Bauld L, et al. Plain Tobacco Packaging: A Systematic Review. Stirling, Scotland: University of Stirling, 2012.http://phrc.Ishtm.ac.uk/project_ 2011-2016_006.html

9 Stead M, Moodie C, Angus K, et al. Is consumer response to plain/standardised tobacco packaging consistent with framework convention on tobacco control guidelines? A systematic review of quantitative studies. PLOS ONE 2013; 8:e75919.

10 Australian Institute of Health and Welfare. Tobacco smoking (NDSHS 2013 key findings). Bruce, ACT: Australian Institute of Health and Welfare, 2013. [23 Jul 2014]. http://www.aihw.gov.au/alcohol-and-other-drugs/ndshs/2013/tobacco/

11 Hammond D. Health warning messages on tobacco products: A review. Tobacco Control 2011;20:327-37.

12 Dunlop SM, Cotter TF, Perez DA. Impact of the 2010 tobacco tax increase in Australia on short-term smoking cessation: a continuous tracking survey. Med J Aust 2011;195:469-72.

13 Dunlop SM, Perez D, Cotter T. Australian smokers' and recent quitters' responses to the increasing price of cigarettes in the context of a tobacco tax increase. Addiction 2011;106:1687-95.

14 Patel V, Nowostawski M, Thomson G, et al. Developing a smartphone 'app' for public health research: the example of measuring observed smoking in vehicles. J Epidemiol Community Health 2013;67:446-52.

15 Thomson G, Russell M, Jenkin G, et al. Informing outdoor smokefree policy: methods for measuring the proportion of people smoking in outdoor public areas. Health Place 2013;20:19-24.

16 Pearson AL, Nutsford D, Thomson G. Measuring visual exposure to smoking behaviours: a viewshed analysis of smoking at outdoor bars and cafes across a capital city's downtown area. BMC Public Health 2014;14:300.

17 Alesci NL, Forster JL, Blaine T. Smoking visibility, perceived acceptability, and frequency in various locations among youth and adults. Prev Med 2003;36: 272-81.

18 Erblich J, Montgomery GH. Cue-induced cigarette cravings and smoking cessation: the role of expectancies. Nicotine Tob Res 2012;14:809-15.

19 Ferguson SG, Shiffman S. The relevance and treatment of cue-induced cravings in tobacco dependence. J Subst Abuse Treat 2009:36:235-43. 